\title{
RESEARCH
}

\section{Effect of different angiotensin-converting-enzyme inhibitors on mortality among elderly patients with congestive heart failure}

\author{
Louise Pilote MD PhD, Michal Abrahamowicz PhD, Mark Eisenberg MD MPH, Karin Humphries DSc, \\ Hassan Behlouli MSc PhD, Jack V. Tu MD PhD
}

$\infty$

See related article page I3i 6

\section{ABSTRACT}

Background: Existing clinical trial data do not address whether all angiotensin-converting-enzyme (ACE) inhibitors are similarly beneficial in improving survival and reducing the rate of readmission among patients with congestive heart failure. We sought to answer this question using administrative databases from Canada's 3 most populous provinces.

Methods: Using linked hospital discharge and prescription claims databases in Quebec, Ontario and British Columbia, we identified all patients $\sigma_{5}$ years or older who were admitted to hospital because of congestive heart failure between Jan. 1, 1998, and Mar. 31, 2002, and who had not been admitted for the same reason in the 3 years preceding the study period. We analyzed the association between the type of ACE inhibitor prescribed within 30 days after discharge and subsequent mortality using Cox proportional hazards models. We then adjusted for demographic, clinical, physician and hospital-related variables, with additional time-dependent variables representing current drug use and dosage. We chose ramipril as the reference category for comparison with the other ACE inhibitors because it has increasingly been prescribed to patients with congestive heart failure.

Results: A total of 43316 patients with congestive heart failure filled prescriptions for ACE inhibitors within 30 days after discharge from hospital. Demographic, clinical and prescription-related characteristics were similar among users of each type of ACE inhibitor. In the time-dependent model, the mortality associated with 5 ACE inhibitors was similar to that with ramipril: adjusted hazard ratios (and $95 \%$ confidence intervals $[\mathrm{Cls}]$ ) were $0.95(0.89-1.02)$ for lisinopril, 0.92 (0.85-1.00) for fosinopril, 0.99 (0.88-1.11) for quinapril, $0.90\left(0.77^{-1.06)}\right.$ for perindopril and 1.00 (o.80-1.24) for cilazapril. However, use of enalapril or captopril was associated with higher mortality compared with ramipril: adjusted hazard ratios (and $95 \% \mathrm{Cls}$ ) were $\mathbf{1 . 1 0}$ (1.04-1.16) for enalapril and $1.13(1.01-1.26)$ for captopril.
Interpretation: When prescribing ACE inhibitors to patients, physicians should consider a possible $10 \%-15 \%$ increase in mortality with captopril and enalapril compared with ramipril among patients with congestive heart failure.

Une version française de ce résumé est disponible à l'adresse www.cmaj.ca/cgi/content/full/178/10/1303/DCI

\section{CMAJ 2008;178(10):1303-II}

$\mathrm{N}$ umerous randomized clinical trials have shown that angiotensin-converting-enzyme (ACE) inhibitors improve survival and reduce the rate of readmission to hospital among patients with congestive heart failure.$^{1-7}$ However, there is considerable debate as to whether each ACE inhibitor exerts the same degree of benefit, especially because not all ACE inhibitors have been studied in this patient population. ${ }^{8-10}$ Most published clinical trials did not address the question of whether such a class effect exists because they focused on comparisons of a particular ACE inhibitor with placebo. In addition, there is a paucity of relevant clinical trial data on ACE inhibitors used in practice.

Although results from a meta-analysis ${ }^{11}$ and a few head-tohead trials ${ }^{12-14}$ suggest that various ACE inhibitors are associated with similar reductions in mortality, other head-to-head trials ${ }^{15,16}$ and observational studies ${ }^{17,18}$ have provided evidence to the contrary. Moreover, ACE inhibitors differ in terms of their chemical structures, half-lives, routes of elimination, bioavailability and degrees of tissue penetration. ${ }^{19}$ These dis-

From the Division of Internal Medicine and Epidemiology (Pilote, Abrahamowicz, Behlouli), Montreal General Hospital, Montréal, Que.; the Department of Epidemiology, Biostatistics and Occupational Health (Abrahamowicz), McGill University, Montréal, Que.; the Divisions of Epidemiology and Cardiology (Eisenberg), Sir Mortimer B. Davis-Jewish General Hospital, Montréal, Que.; the Division of Cardiology, University of British Columbia, and the Centre for Health Evaluation and Outcome Sciences (Humphries), Vancouver, BC; and the Institute for Clinical Evaluative Sciences (Tu), Sunnybrook Health Sciences Centre, Toronto Ont. 
tinct pharmacokinetic and pharmacodynamic characteristics may result in varying effectiveness. It has been questioned whether the same beneficial effects would be observed with ACE inhibitors with lower degrees of tissue penetration. ${ }^{9} \mathrm{Lab}-$ oratory studies have suggested that higher degrees of tissue penetration are associated with more favourable levels of fibrinolytic markers in vascular tissue. ${ }^{20}$ Yet, in practice, different physicians seem to prefer prescribing different ACE inhibitors to patients with congestive heart failure.

It is unlikely that a head-to-head trial of all ACE inhibitors currently prescribed to patients with congestive heart failure will be conducted. Moreover, if the effects of various ACE inhibitors differ, the differences are likely to be relatively small, which means a very large sample would be required to ensure adequate statistical power when comparing the efficacy of the drugs. Thus, we used large population-based administrative databases of hospital discharge and prescription claims data to determine whether all ACE inhibitors are associated with similar reductions in mortality among patients admitted to hospital because of congestive heart failure.

\section{Methods}

\section{Study population and data sources}

We searched government administrative databases of hospital discharges in 3 provinces (Maintenance et exploitation des données pour l'étude de la clientèle hospitalière [Med-Echo] in Quebec, the Canadian Institute for Health Information in Ontario and the Patient Hospitalization Database in British Columbia) for data on the treatment and clinical outcomes of all patients who were admitted to hospital because of congestive heart failure between Jan. I, I998, and Mar. 3I, 2002, and who had not had been admitted for this reason within the 3 years before the study period. We imposed this 3 -year exclusion period to ensure that almost all patients who had previously been admitted to hospital because of congestive heart failure were excluded. ${ }^{21}$ We followed patients until Dec. 3I, 2002, to ensure at least 9 months of potential follow-up. Eligible patients were those admitted to hospital with a primary diagnosis of congestive heart failure (International Classification of Diseases [ICD-9] code 428). We excluded admissions that represented a hospital transfer, admissions to a nonacute hospital setting and admissions where congestive heart failure was the secondary diagnosis. We also excluded patients younger than 65 years or older than I0 5 years.

Using encrypted provincial health insurance numbers, we linked the data from these databases to data from the provincial drug claims databases (la Régie de l'assurance maladie $d u$ Québec, the Ontario Drug Benefit Plan database and BC PharmaCare), which contain information on patients' drug prescriptions.

By combining information from both the Med-Echo and Régie de l'assurance maladie du Québec databases, we obtained complete survival data for patients in Quebec: deaths that occur in hospital are recorded in the Med-Echo database, and those that occur both in and out of hospital are recorded in the Régie de l'assurance maladie du Québec database. The Ontario Registered Persons Database contained information on the vital status of all residents covered under the Ontario Health Insurance Plan. Linkage with the deaths registry of the British Columbia Vital Statistics Agency provided mortality data. The accuracy of the survival data for patients in Ontario with acute myocardial infarction has previously been verified by linking directly to vital statistics data housed at Cancer Care Ontario, with an agreement of $99.6 \% .^{22}$ The accuracy of the Quebec data has been similarly investigated. ${ }^{23}$ The accuracy of survival data for patients in British Columbia with acute myocardial infarction has been ascertained by linking the $\mathrm{BC}$ Cardiac Registries database with the Vital Statistics Agency. Using probabilistic linkage, we were able to achieve a $95.7 \%$ match for 30 -day mortality, and a $99.8 \%$ match for I-year mortality. ${ }^{24}$

\section{Prescription groups}

Using the linked databases, we identified patients with congestive heart failure who filled at least I prescription for an ACE inhibitor within 30 days after discharge from hospital. Most patients in our database filled their prescriptions on the same day as discharge, with a median time to first prescription of 0 days. We used a timeframe of 30 days to capture patients who filled their prescriptions at a later date. We categorized the patients into groups based on the first type of ACE inhibitor they received after discharge. We studied the most commonly used ACE inhibitors (ramipril, lisinopril, fosinopril, quinapril, enalapril, captopril, perindopril and cilazapril), but did not evaluate trandopril, benazepril, or the combination of an ACE inhibitor with either a diuretic or calcium-channel blocker.

\section{Prescription characteristics}

For each patient included in the study, we obtained detailed information about all prescriptions filled over the subsequent follow-up period. In all 3 provinces, this information included the number of prescriptions filled. From the Quebec and Ontario databases, we were also able to obtain data on the daily dose, as well as the duration of the prescription in days. We also examined whether the dose was at or above the target dose for each drug. For the ACE inhibitors that have been previously evaluated in clinical trials involving patients with congestive heart failure (ramipril, lisinopril, fosinopril, quinapril, enalapril and captopril), we used the target doses studied in those trials for comparison. For the others (perindopril and cilazapril), we used the target doses listed in the 2006 edition of the Compendium of Pharmaceuticals and Specialties. ${ }^{25}$

Finally, to examine patients' adherence to ACE inhibitor therapy, we calculated the percentage of time for which each patient was covered by an ACE inhibitor prescription during the first year after discharge from hospital, or until his or her death if the patient died during that year, and compared the results with the duration of each filled prescription during the same period.

\section{Fixed and time-dependent covariates}

We selected a number of fixed baseline covariates a priori for inclusion in our multivariable models because of their possible influence on survival and other clinical outcomes following hospital admission because of congestive heart failure, ${ }^{26}$ and their possible association with prescription practices for specific ACE inhibitors. We used the secondary diagnoses included in the 
hospital discharge databases to obtain data about patients' inhospital comorbidities: hypertension, chronic obstructive pulmonary disease or other respiratory disease, atrial fibrillation and flutter, acute myocardial infarction, diabetes, renal disease, cerebrovascular disease, peripheral vascular disease, primary or metastatic cancer, dementia, rheumatologic disease and liver disease. We obtained data on cardiac procedures (cardiac catheterization, percutaneous coronary intervention, coronary artery bypass graft) performed between the date of hospital admission and the date that the first ACE inhibitor prescription was filled, as well as data on prescriptions for other drugs (loop diuretics, spironolactone, metolazone or other diuretics; nitrates; $\beta$-blockers; digoxin; warfarin; calcium-channel blockers; lipid-lowering agents; amiodarone; ticlopidine or clopidogrel; angiotensin II receptor blockers; or hydralazine) filled between the date of discharge and first ACE inhibitor prescription. We also recorded the specialty of the treating physician (family medicine, cardiology, internal medicine, other specialty). In addition, we adjusted for the teaching status of the hospital of admission and noted whether the annual volume of admissions because of congestive heart failure at the study hospitals was low (3I admissions or fewer), medium (3I-I2I admissions) or high (more than I2I admissions).

We also used information on dose and duration of prescriptions for ACE inhibitors to create 2 binary timedependent variables. One variable indicated current use of the initially prescribed drug based on the dates and durations of consecutive prescriptions. The other variable indicated whether the current dose of each ACE inhibitor was at or above the target dose.

\section{Statistical analyses}

We first compared all patient characteristics according to the type of ACE inhibitor prescribed within 30 days after discharge from hospital. Main analyses relied on methodology for survival analysis. We defined time-to-event as time elapsed between the first ACE inhibitor prescription and death. We censored data for patients who were alive on Dec. 3I, 2002, at that time. We also censored data for patients who switched to another ACE inhibitor during follow-up on the date of the switch. We used the Kaplan-Meier method to estimate nonadjusted mortality by type of ACE inhibitor initially prescribed, and we used the log-rank test to compare the groups.

We used 2 versions of the multivariable Cox proportional hazards model ${ }^{27}$ to account for differences in duration of follow-up and to control for differences in the distribution of covariates across the prescription groups. In both models, we adjusted for the associations between each type of ACE inhibitor and mortality for the fixed baseline covariates described in the previous section. We also adjusted for the calendar year of hospital admission to account for possible temporal trends, the time from discharge to filling the first ACE inhibitor prescription, length of stay and the province of admission. In the second model, we adjusted for 2 additional time-dependent variables: changes in dose, and periods on and off the ACE inhibitors. Because ramipril has increasingly been prescribed to patients with congestive heart failure, we selected ramipril as the reference category for comparisons with the other ACE inhibitors, each of which was represented by a dummy variable. We used a goodness-of-fit test (7 degrees of freedom) to test the global null hypothesis that all $8 \mathrm{ACE}$ inhibitors were associated with the same mortality.

First, we fitted the fixed-exposure model to data from all 3 provinces, with drug exposure modelled by fixed-in-time covariates representing the type of ACE inhibitor initially prescribed. Thus, in the fixed-exposure model, exposure status did not change during the follow-up even if the patients interrupted or discontinued the use of the initially prescribed medication.

Next, we fitted the time-dependent model, which included 2 additional binary time-dependent variables representing current use of the initially prescribed ACE inhibitor, and cur-

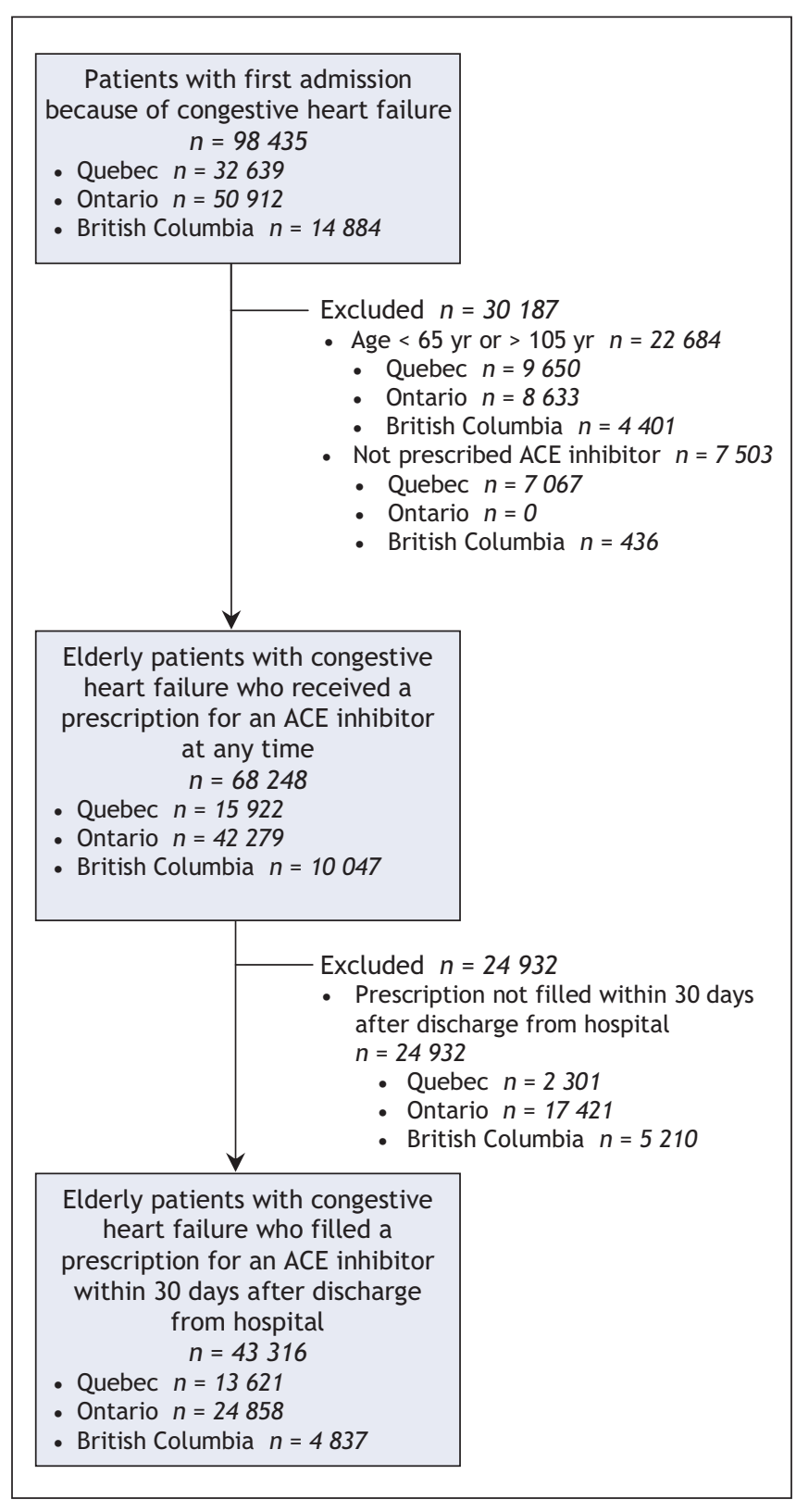

Figure 1: Selection of patient data to include in analysis of mortality associated with individual angiotensin-converting-enzyme (ACE) inhibitors among patients with congestive heart failure. 
rent dose at or above the target dose. Thus, the timedependent model accounted for potential differences in the exposure duration, temporal pattern of drug use versus nonuse, and drug dose among the different ACE inhibitors. ${ }^{28}$ Because the data from British Columbia did not include information on prescription duration, we limited the timedependent analyses to data from Ontario and Quebec.

In both models, we tested the proportional hazards assumption for each independent variable using the nonparametric test proposed by Grambsch and Therneau. ${ }^{29}$ For those covariates, for which the proportional hazards hypothesis was rejected at $\alpha=0.05$, we included a time-by-covariate interaction to account for variation of its effect over time. ${ }^{30}$

\section{Sensitivity analyses}

To test the robustness of our results, we performed several additional analyses. First, we tested for interactions between the effects of ACE inhibitors on mortality and province. Furthermore, we tested in separate models whether the differences in mortality among users of individual ACE inhibitors were modified by some other clinical or demographic characteristics. To this end, we expanded the fixed-exposure multivariable model by adding 7 interactions between a given covariate and each of the 7 dummy indicators of ACE inhibitors. We then used a goodness-of-fit test (7 degrees of freedom) to determine whether adding the 7 interactions significantly improved the model's fit to data. Finally, we assessed whether adjusting for the comorbidities identified during the 5 years preceding and including the hospital admission changed the estimated effects of ACE inhibitors on mortality.

\section{Results}

\section{Study population}

A total of 433 I 6 patients admitted to hospital because of congestive heart failure filled their first prescription for an ACE inhibitor within 30 days after discharge from hospital (Figure I). Among these patients, ramipril was most fre-

Table 1: Demographic, clinical, physician- and hospital-related characteristics of 43316 patients with congestive heart failure who received prescriptions for ACE inhibitors (part 1 of 2 )

\begin{tabular}{|c|c|c|c|c|c|c|c|c|}
\hline Characteristic & \multicolumn{8}{|c|}{ ACE inhibitor; \% of patients* } \\
\hline Age, yr, median & 78 & 79 & 78 & 78 & 79 & 78 & 78 & 79 \\
\hline Follow-up, d, median & 597 & 759 & 784 & 708 & 705 & 732 & 776 & 717 \\
\hline Male & 49 & 47 & 47 & 50 & 48 & 48 & 48 & 49 \\
\hline Hypertension & 29 & 27 & 31 & 31 & 22 & 31 & 31 & 29 \\
\hline $\begin{array}{l}\text { Chronic obstructive pulmonary } \\
\text { disease or other respiratory } \\
\text { disease }\end{array}$ & 21 & 23 & 24 & 24 & 21 & 22 & 23 & 28 \\
\hline Atrial fibrillation and flutter & 30 & 28 & 32 & 33 & 27 & 29 & 37 & 34 \\
\hline Cerebrovascular disease & 5 & 6 & 6 & 7 & 5 & 5 & 8 & 6 \\
\hline Peripheral vascular disease & 4 & 4 & 5 & 6 & 4 & 4 & 5 & 5 \\
\hline Primary or metastatic cancer & 4 & 3 & 3 & 4 & 4 & 3 & 3 & 2 \\
\hline Dementia & 2 & 3 & 3 & 3 & 2 & 2 & 3 & 2 \\
\hline Rheumatologic disease & 2 & 1 & 1 & 2 & 1 & 1 & 2 & 2 \\
\hline Liver disease & 0 & 1 & 1 & 0 & 0 & 1 & 1 & 1 \\
\hline \multicolumn{9}{|l|}{$\begin{array}{l}\text { Procedures between admission } \\
\text { and first ACE inhibitor prescription }\end{array}$} \\
\hline Catheterization & 6 & 4 & 4 & 4 & 4 & 4 & 6 & 3 \\
\hline $\begin{array}{l}\text { Percutaneous coronary } \\
\text { intervention }\end{array}$ & 1 & 0 & 1 & 1 & 1 & 1 & 1 & 1 \\
\hline \multicolumn{9}{|c|}{$\begin{array}{l}\text { Other prescriptions between discharge } \\
\text { and ACE inhibitor prescription }\end{array}$} \\
\hline
\end{tabular}


quently prescribed (34\%), followed by enalapril ( $29 \%)$, lisinopril ( $16 \%)$, fosinopril ( $9 \%)$, captopril $(5 \%)$, quinapril $(5 \%)$, perindopril (2\%) and cilazapril ( $1 \%)$. About I0\% of patients switched to another ACE inhibitor within the year after discharge. This percentage grew to $17 \%$ of patients by the end of the follow-up period. The mean follow-up period for all study patients was 752 days (2.I years [standard deviation I.2 years]) from the time of admission, yielding a total of 89243 patient-years of follow-up.

\section{Prescription groups}

Table I describes the demographic, clinical, physician and hospital characteristics of the patients. Baseline characteristics among the prescription groups were similar, which suggested the absence of a preferential prescribing pattern for patients with poorer or better health status. One exception was that patients taking fosinopril, an ACE inhibitor with low renal clearance, were more likely to have renal disease than patients prescribed another ACE inhibitor. In terms of other prescriptions received between hospital discharge and the initial ACE inhibitor prescription, patients using ramipril were more likely to have received prescriptions for $\beta$-blockers and spironolactone than patients taking other ACE inhibitors. However, the percentage of patients using any type of diuretic was similar among all prescription groups (Table I).

\section{Prescription characteristics}

Table 2 compares prescription characteristics by type of ACE inhibitor during the year following discharge. The median number of ACE inhibitor prescriptions filled was similar across the groups. Adherence was good in all the groups, with mean coverage by ACE inhibitor prescriptions for most of the year after discharge (min-max $72 \%-81 \%$ ). The majority of patients (more than $80 \%$ ) had prescription coverage for at least $80 \%$ of the year, except for patients taking captopril, $58 \%$ of whom had this degree of coverage. Small percentages of patients prescribed ramipril, lisinopril, fosinopril, quinapril, enalapril or captopril received a dose that was at or

Table 1: Demographic, clinical, physician- and hospital-related characteristics of 43316 patients with congestive heart failure who received prescriptions for ACE inhibitors (part 2 of 2)

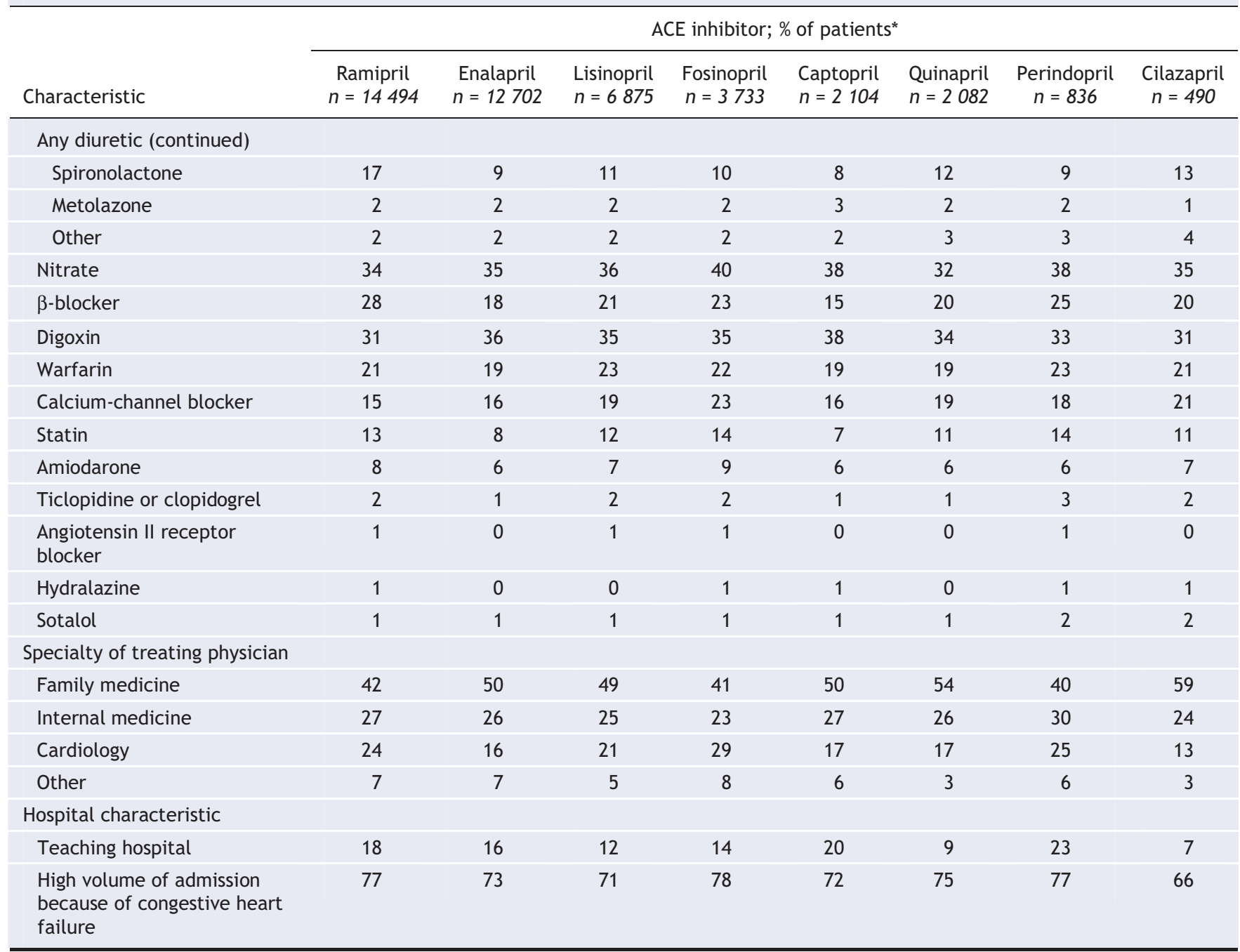

Note: $\mathrm{ACE}=$ angiotensin-converting-enzyme.

*Unless stated otherwise. 
above the recommended target dose; $77 \%$ of patients prescribed perindopril and $93 \%$ of those prescribed cilazapril received doses at or above the recommended target (Table 2).

\section{Mortality outcomes}

During the follow-up period, a total of 16618 patients died: I664 in British Columbia, 991o in Ontario and 5044 in Quebec. The unadjusted incidence of death ranged from 15.7 per Ioo patients per year to 19.9 per Ioo patients per year (Table 3). The overall unadjusted yearly rate of death was $2 \mathrm{I} .5 \%$. The unadjusted probability of survival was significantly lower among patients prescribed enalapril or captopril than among patients prescribed ramipril $(p<0.00$ I for the log-rank test) (Figure 2). The difference in survival was not significant for the other ACE inhibitors relative to ramipril.

The fixed-exposure and time-dependent multivariable Cox proportional hazards models confirmed the statistically significant differences in mortality among the different ACE in- hibitor groups $(p<0.001$ for goodness-of-fit test in both models) (Figure 3 ).

In the time-dependent model, enalapril and captopril were associated with a higher mortality relative to ramipril: the hazard ratio (and 95\% confidence intervals [CIs]) were I.Io (I.04-I.I6) for enalapril and I.I3 (I.oI-I.26) for captopril (Figure 3). All of the other ACE inhibitors were associated with a similar mortality as ramipril. Both current use (hazard ratio $0.42,95 \% \mathrm{CI} 0.40-0.44$ ) and current dose at or above target (hazard ratio 0.88 , 95\% CI 0.84-0.92) were independent predictors of lower mortality. In the sensitivity analyses, we found that the hazard ratios for enalapril and captopril were higher in Ontario than in Quebec and British Columbia; however, in all 3 provinces the direction of their effects were the same (data not shown). For each of the other covariates, the goodness-of-fit test ( $p>0.05 ; 7$ degrees of freedom) indicated that the effects of ACE inhibitors did not differ depending on the patient characteristics.

Table 2: Prescription characteristics for 43316 patients who received prescriptions for ACE inhibitors after discharge

\begin{tabular}{|c|c|c|c|c|c|c|c|c|}
\hline Characteristic & \multicolumn{8}{|c|}{ ACE inhibitor } \\
\hline $\begin{array}{l}\text { No. of prescriptions filled } \\
\text { within } 1 \text { year after } \\
\text { discharge, median }\end{array}$ & 6 & 6 & 7 & 7 & 6 & 6 & 7 & 6 \\
\hline $\begin{array}{l}\text { Persistence, mean, \% of } \\
\text { time† }\end{array}$ & 81 & 78 & 80 & 78 & 72 & 81 & 76 & 75 \\
\hline $\begin{array}{l}\text { High persistence, mean, } \\
\% \text { of patientsł }\end{array}$ & 71 & 66 & 70 & 66 & 58 & 71 & 64 & 61 \\
\hline
\end{tabular}

Note: $\mathrm{ACE}=$ angiotensin-converting-enzyme.

*Dosage values are based on an average of all prescriptions.

†Persistence is a measure of adherence and is defined as the percentage of time for which a patient was covered by ACE inhibitor prescription over the year following discharge, or until death if the patient died within the year.

¥High persistence is defined as having a persistence $\geq 80 \%$.

Table 3: Follow-up and all-cause mortality among 43316 patients with congestive heart failure who received prescriptions for ACE inhibitors

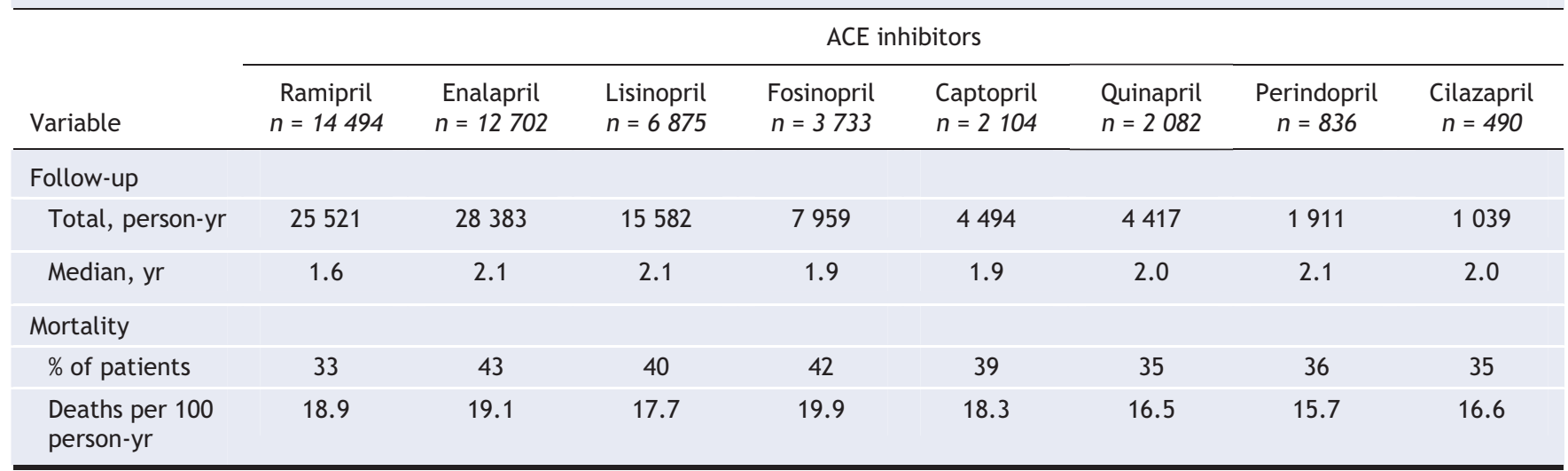

Note: $\mathrm{ACE}=$ angiotensin-converting-enzyme. 
We limited additional sensitivity analyses to the Quebec data because data from other provinces were not available at the time of analysis and because not all data were required for sensitivity analyses. The proportional hazards hypothesis was not rejected for any of the ACE inhibitors (all $p$ values >0.15), which indicated that the adjusted hazard ratios reported in Figure 3 remain relatively constant for up to 5 years of followup. Four covariates (primary or metastatic cancer, chronic obstructive pulmonary disease or other respiratory disease, dementia, and amiodarone use) did not follow the proportional hazards hypothesis; however, adjusting for these covariates did not change the estimated effects of any ACE inhibitor (data not shown). Furthermore, the results reported in Figure 3 remained almost unchanged when we adjusted for comorbidities that we identified based on any admission to hospital in the 5 years preceding the study (data not shown).

\section{Interpretation}

Our study shows that, at currently prescribed doses, enalapril and captopril were associated with about 10\%-15\% higher mortality than ramipril among elderly patients with congestive heart failure. Patients who filled prescriptions for fosinopril, lisinopril, quinapril, perindopril and cilazapril did not have a significantly different mortality than those who filled prescriptions for ramipril. For fosinopril, lisinopril and quinapril, we had adequate $(80 \%$ or higher) power to detect a hazard ratio of I.Io relative to ramipril. The hazard ratios detectable with $80 \%$ power were 1.13 for perindopril and I.I8 for cilazapril, which indicated that moderate but clinically important differences in mortality cannot be ruled out. In addition, the results reported in Figure 3 suggest that the relative risk of death associated with captopril (the ACE inhibitor with the highest estimated hazard ratio) may be about $23 \%$ greater $(1.13 / 0.92=1.23)$ relative to fosinopril (the ACE inhibitor with the lowest estimated hazard). Although we cannot provide definitive answers regarding relative safety for all possible pairs of ACE inhibitors, we can conclude from our findings that mortality was higher among patients who were taking captopril or enalapril than among patients taking ramipril; that mortality among patients taking fosinopril, lisinopril or quinapril was similar to that among patients taking ramipril; and that the results were inconclusive for patients taking perindopril or cilazapril. Our real-world analysis provides important comparative information that would not be readily available in a clinical trial. Moreover, it is unlikely that a clinical trial will ever compare 8 different ACE inhibitors.

In previous studies, the comparison of various ACE inhibitors yielded conflicting results, largely related to the different outcome measures. Captopril was compared with quinapril ${ }^{12}$ and lisinopril ${ }^{13}$ in separate trials involving patients with congestive heart failure, and in both cases similar effects among the drugs were observed. However, lisinopril and captopril were also compared in a randomized trial involving patients with congestive heart failure, which concluded that, compared with captopril, lisinopril improved nonfatal outcomes such as exercise duration in certain subgroups of patients. ${ }^{15}$

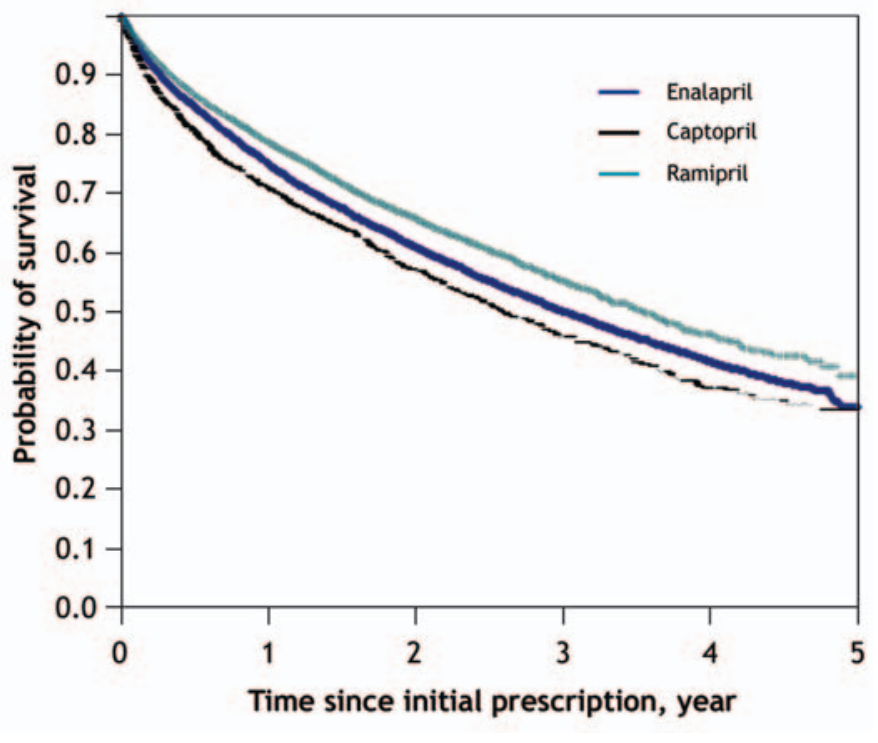

Figure 2: Unadjusted Kaplan-Meier 5-year survival curves for patients prescribed an angiotensin-converting-enzyme (ACE) inhibitor within 30 days after discharge from hospital. Data are shown for ACE inhibitors for which a significant difference in survival was observed relative to ramipril.

A class effect implies that all drugs in a class exert the same effect, positive or negative, on their target population. There may be several reasons for the different effects in our study. The higher mortality associated with enalapril or captopril relative to ramipril could be related to their dosages: these drugs have to be used multiple times per day, with the potential for shorter durations of action, for periods when the drug is not active and for reduced adherence. As a result, the effectiveness of these medications in the population at large may be inferior to medications that are taken once daily.

Another potential explanation for these contrasting effects is that the benefits of ACE inhibitors may depend on specific pharmacologic properties and structural characteristics of these drugs. In particular, the issue of tissue penetration could explain the varying effects. For example, in patients with acute myocardial infarction, ACE inhibitors stabilize plaques, a benefit that has been purported to be associated with their degree of tissue penetration..$^{20}$ Evidence of such a benefit is suggested by the ability of ramipril, which has a high degree of tissue penetration, to prevent mortality and cardiac events among high-risk patients without congestive heart failure. ${ }^{31}$ Similarly, perindopril, which also has a high degree of tissue penetration, was shown to reduce rates of cardiac events among low-risk patients without congestive heart failure. ${ }^{32}$ Quinapril, which in our analyses was associated with mortality similar to that of ramipril, and trandolopril also have high degrees of tissue penetration. It is possible that the benefit of a higher degree of tissue penetration may not be as relevant for patients with congestive heart failure as improved hemodynamic and ventricular remodelling; however, there is limited evidence to support this hypothesis. First, a trial specifically designed to compare outcomes among cardiac patients prescribed ACE inhibitors with high 
versus low degrees of tissue penetration has not been conducted. Thus, the clinical importance of differences in tissue penetration among ACE inhibitors has not been fully established in patients with either acute myocardial infarction or congestive heart failure. ${ }^{19}$ Second, although the degrees of tissue penetration of a number of ACE inhibitors have been directly compared in an older study, ${ }^{33}$ to the best of our knowledge, no study has compared the tissue penetration of all ACE inhibitors that are currently prescribed to patients with congestive heart failure.

Although our large database study permits analyses of patterns and outcomes of ACE inhibitor use at the population level with adequate statistical power, its main limitation is that it does not contain information on some clinically relevant patient characteristics. For example, we did not have information on ejection fraction or on systolic versus diastolic dysfunction. However, we adjusted for several important demographic, clinical, physician and hospital-related variables associated with outcomes in patients with congestive heart failure, as well as for the current prescription drug use and dosage, which were both represented by time-dependent variables. In addition, we focused only on patients who received prescriptions for ACE inhibitors, minimizing con- founding by indication. ${ }^{34}$ Nonetheless, there remains the possibility that certain ACE inhibitors were preferentially prescribed to patients with low ejection fraction, or to patients with systolic versus diastolic dysfunction. For example, enalapril could be preferentially given to patients with systolic dysfunction who are thought to have a worse prognosis.

Other missing variables, such as smoking, were unlikely to be distributed differentially across ACE inhibitor groups and, thus, were unlikely to introduce bias in our results. Also, although prescription dosages varied for the ACE inhibitors, the time-dependent variables accounted for the different dosages over time, and there was no interaction between dosages and the different ACE inhibitors, which indicated that the impact of dosage was the same for all drugs. The time-dependent model also accounted for periods on or off the drug. In fact, the difference in hazard ratios that we observed in the time-dependent model accounts for drug interruption, whereas the fixed-effect model assumes a continuous exposure.

Finally, data linkages were not 100\% for the mortality variable, but they were unlikely to differ across specific study medications. A similar study that used administrative data to study the effectiveness of various ACE inhibitors concluded

$\begin{array}{lc}\text { ACE inhibitor } & \text { Hazard ratio }(95 \% \mathrm{Cl}) \\ \text { Ramipril (reference) } & 1.00 \\ \text { Enalapril } & \\ \quad \text { Fixed-exposure model } & 1.36(1.3-1.41) \\ \quad \text { Time-dependent model } & 1.1(1.04-1.16) \\ \text { Lisinopril } & \\ \quad \text { Fixed-exposure model } & 1.2(1.14-1.26) \\ \quad \text { Time-dependent model } & 0.95(0.89-1.02) \\ \text { Fosinopril } & \\ \quad \text { Fixed-exposure model } & 1.22(1.15-1.29) \\ \quad \text { Time-dependent model } & 0.92(0.85-1.00) \\ \text { Captopril } & \\ \quad \text { Fixed-exposure model } & 1.61(1.50-1.74) \\ \quad \text { Time-dependent model } & 1.13(1.01-1.26) \\ \text { Quinapril } & \\ \text { Fixed-exposure model } & 1.1(1.02-1.19) \\ \quad \text { Time-dependent model } & 0.99(0.88-1.11) \\ \text { Perindopril } & \\ \text { Fixed-exposure model } & 1.06(0.95-1.20) \\ \text { Time-dependent model } & 0.90(0.77-1.06) \\ \text { Cilazapril } & \\ \text { Fixed-exposure model } & 1.08(0.93-1.26) \\ \text { Time-dependent model } & 1.00(0.80-1.24)\end{array}$

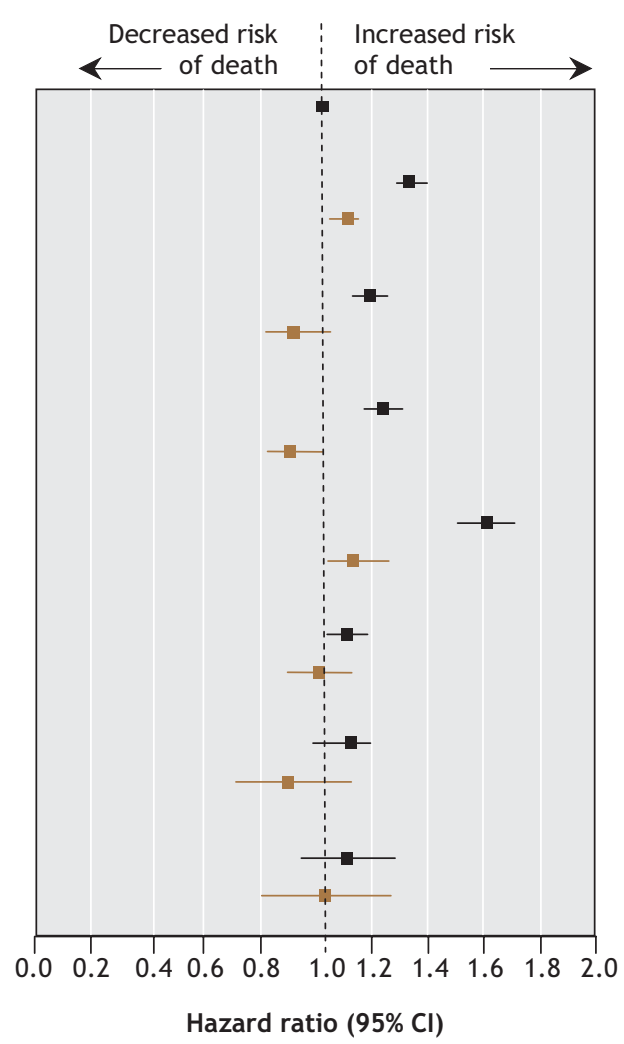

Figure 3: Effect of various ACE inhibitors on all-cause mortality among patients with congestive heart failure. Variables included in the models: fiscal year of admission, province of admission, length of stay, time to first ACE inhibitor prescription, specialty of treating physician, hospital characteristics (teaching v. nonteaching, volume of admissions because of congestive heart failure), comorbidities and prescriptions filled for other cardiac medications). The fixed-exposure model includes data from Quebec, Ontario and British Columbia. The time-dependent model includes data from Quebec and Ontario only. $\mathrm{Cl}=$ confidence interval. 
that they have a class effect. ${ }^{35}$ The robustness of results from observational studies is highly dependent on the nature of the analysis. We believe our use of a time-dependent variable analysis best reflects the dosage and patterns of ACE inhibitor use. The lack of application of this method in the previous study may explain its different conclusions.

In summary, our results suggest that physicians choosing an ACE inhibitor for patients with congestive heart failure should consider the possible $10 \%-15 \%$ increase in mortality that we observed with enalapril and captopril use compared with ramipril use. Further evidence is required to fully assess the comparability between ramipril and all newer ACE inhibitors.

This article has been peer reviewed.

Competing interests: None declared.

Contributors: All of the authors contributed to the conception and design of the study, acquisition and interpretation of the data, and drafting and revising of the manuscript. All of the authors approved the final version of the manuscript for publication.

Acknowledgements: We thank Hugues Richard, Yanyan Gong and Aihua Pu for their assistance with statistical programming.

Louise Pilote is a chercheur-boursier of the Fonds de recherche en santé du Québec (FRSQ) and a James McGill Professor at McGill University. Michal Abrahamowicz is a James McGill Professor at McGill University. Mark Eisenberg is a chercheur-boursier of the FRSQ. Karin Humphries is a Scholar of the Michael Smith Foundation. Jack Tu is a Research Chair in Health Services Research of the Canadian Institutes for Health Research.

This study was funded by grant MOP-5318I from the Canadian Institutes of Health Research.

\section{REFERENCES}

I. CONSENSUS Trial Study Group. Effects of enalapril on mortality in severe congestive heart failure: Results of the Cooperative North Scandinavian Enalapril Survival Study (CONSENSUS). N Engl J Med ig87;316:1429-35.

2. SOLVD Investigators. Effect of enalapril on survival in patients with reduced left ventricular ejection fractions and congestive heart failure. N Engl J Med I99I;325: 293-302.

3. Pfeffer MA, Braunwald E, Moyé LA, et al. Effect of captopril on mortality and morbidity in patients with left-ventricular dysfunction after myocardial-infarction results of the Survival and Ventricular Enlargement Trial. N Engl J Med 1992;327 $669-77$.

4. Acute Infarction Ramipril Efficacy (AIRE) Study investigators. Effect of ramipril on mortality and morbidity of survivors of acute myocardial infarction with clinical evidence of heart failure. Lancet I993;342:82I-8

5. Gruppo Italiano per lo Studio della Sopravvivenza nell'Infarto Miocardico. GISSI3: effects of lisinopril and transdermal glyceryl trinitrate singly and together on 6 week mortality and ventricular function after acute myocardial infarction. Lancet I994;343:III5-22.

6. ISIS-4 (Fourth International Study of Infarct Survival) Collaborative Group. ISIS-4 a randomised factorial trial assessing early oral captopril, oral mononitrate, and intravenous magnesium sulphate in 58 o50 patients with suspected acute myocardial infarction. Lancet $1995 ; 345: 669-85$.

7. Kober L, Torp-Pedersen C, Carlsen JE, et al. A clinical-trial of the angiotensinconverting enzyme inhibitor trandolapril in patients with left-ventricular dysfunction after myocardial infarction. N Engl J Med I995;333:1670-6.

8. Furberg $\mathrm{CD}$, Pitt $\mathrm{B}$. Are all angiotensin-converting enzyme inhibitors interchangeable? J Am Coll Cardiol 2001;37:1456-6o.

9. Sica DA. The Heart Outcomes Prevention Evaluation study: angiotensin-converting enzyme inhibitors: Are their benefits a class effect or do individual agents differ? Curr Opin Nephrol Hypertens 200I;10:597-6or.
Io. Hennessy S, Kimmel S. Is improved survival a class effect of angiotensinconverting enzyme inhibitors? Ann Intern Med 2004;I4I:I57-8.

II. Garg R, Yusuf S; Collaborative Group of ACE Inhibitor Trials. Overview of randomized trials of angiotensin-converting enzyme inhibitors on mortality and morbidity in patients with heart failure. JAMA I995;273:1450-6.

I2. Gavazzi A, Marioni R, Campana C, et al. Comparative trial of quinapril versus captopril in mild to moderate congestive heart failure. J Hypertens I994;I2:S89-93.

I3. Bach R, Zardini P. Long-acting angiotensin-converting enzyme inhibition: oncedaily lisinopril versus twice-daily captopril in mild-to-moderate heart failure. Am Cardiol $1992 ; 70: 70 \mathrm{C}-77 \mathrm{C}$

I4. Borghi C, Ambrosinoni E; Survival of Myocardial Infarction Long-term Evaluation2 Working Party. Double-blind comparison between zofenopril and lisinopril in patients with acute myocardial infarction: results of the Survival of Myocardial Infarction Long-term Evaluation-2 (SMILE-2) study. Am Heart J 2003;I45:80-7.

I5. Giles TD, Katz R, Sullivan JM, et al. Short- and long-acting angiotensin-converting enzyme inhibitors: a randomized trial of lisinopril versus captopril in the treatment of congestive heart failure. J Am Coll Cardiol I989;13:1240-7.

I6. Foy SG, Crozier IG, Turner JG, et al. Comparison of enalapril versus captopril on left ventricular function and survival three months after acute myocardial infarction (the 'PRACTICAL"' study). Am J Cardiol I994;73:1180-6.

I7. Wienbergen H, Schiele R, Gitt A, et al. Impact of ramipril versus other angiotensin-converting enzyme inhibitors on outcome of unselected patients with ST-elevation acute myocardial infarction. Am J Cardiol 2002;90:I045-9.

I8. Pilote L, Abrahamowicz M, Rodrigues E, et al. Mortality rates in elderly patients who take different angiotensin-converting enzyme inhibitors after acute myocardial infarction: A class effect? Ann Intern Med 2004;I4I:I02-I2.

I9. Brown NJ, Vaughan DE. Angiotensin-converting enzyme inhibitors. Circulation I998;97:I4II-20.

20. Tsikouris JP, Suarez JA, Meyerrose GE, et al. Questioning a class effect: Does ACE inhibitor tissue penetration influence the degree of fibrinolytic balance alteration following an acute myocardial infarction? J Clin Pharmacol 2004;44:150-7.

2I. Jong P, Vowinckel E, Liu P, et al. Prognosis and determinants of survival in patients newly hospitalized for heart failure. Arch Intern Med 2002;162:1689-94.

22. Tu JV, Naylor CD, Austin P. Temporal changes in the outcomes of acute myocardial infarction in Ontario, I992-I996. CMAJ I999;I6I:1257-6I.

23. Levy AR, Tamblyn RM, Fitchett $D$, et al. Coding accuracy of hospital discharge data for elderly survivors of myocardial infarction. Can J Cardiol I999;15:1277-82.

24. Ghahramani M, Dean C, Spinelli J. Simultaneous modelling of operative mortality and long-term survival after coronary artery bypass surgery. Stat Med 200I;20: I93I-45.

25. Canadian Pharmacists Association. The Compendium of Pharmaceuticals and Specialties (2006 edition). Ottawa: The Association; 2006.

26. Lee DS, Austin PC, Rouleau JL, et al. Predicting mortality among patients hospitalized for heart failure: derivation and validation of a clinical model. JAMA 2003;290: 258I-7.

27. Cox D. Regression models and life-tables. JR Stat Soc B 1972;34:187-220.

28. Zhou Z, Rahme E, Abrahamowicz M, et al. Survival bias associated with time-totreatment initiation in drug effectiveness evaluation: a comparison of methods. Am J Epidemiol 2005;162:1016-23

29. Grambsch PM, Therneau TM. Proportional hazards tests and diagnostics based on weighted residuals. Biometrika I994;81:515-26.

30. Abrahamowicz M, MacKenzie T, Esdaile JM. Time-dependent hazard ratio: modeling and hypothesis testing with application in lupus nephritis. J Am Stat Assoc I996;9I:I432-9.

31. Heart Outcomes Prevention Evaluation Study Investigators. Effects of an angiotensin-converting-enzyme inhibitor, ramipril, on cardiovascular events in highrisk patients. $N$ Engl J Med 2000;342:145-53.

32. European Trial on Reduction of Cardiac Events with Perindopril in Stable Coronary Artery Disease Investigators. Efficacy of perindopril in reduction of cardiovascular events among patients with stable coronary artery disease: randomised, double-blind, placebo-controlled, multicentre trial (the EUROPA study). Lancet 2003;362:782-8.

33. Johnston CI, Fabris B, Yamada H, et al. Comparative studies of tissue inhibition by angiotensin converting enzyme inhibitors. J Hypertens Suppl I989;7:SII-6.

34. Salas M, Hofman A, Stricker BH. Confounding by indication: an example of variation in the use of epidemiologic terminology. Am J Epidemiol I999;I49:98I-3.

35. Tu K, Mamdani M, Kopp A, et al. Comparison of angiotensin-converting enzyme inhibitors in the treatment of congestive heart failure. Am J Cardiol 2005;95:283-6.

\section{Correspondence to: Dr. Louise Pilote, Divisions of Internal} Medicine and of Clinical Epidemiology, McGill University Health Centre, 687 Pine Ave. W, V Building, Montréal QC $\mathrm{H}_{3} \mathrm{~A}$ IAI; fax 5I4 934-8293; louise.pilote@mcgill.ca 